\title{
ANALISIS PENGARUH KUALITAS PRODUK, PROMOSI, KEPERCAYAAN \\ MEREK, DAN KEPUASAN KONSUMEN TERHADAP KEPUTUSAN \\ PEMBELIAN SEPEDA MOTOR HONDA VARIO \\ (Studi pada pengguna Motor Honda Vario di Kecamatan Muara Bulian)
}

\author{
Siti marlina $A Z^{1}$
}

\begin{abstract}
The purpose of this study was to analyze the influence of the quality of the products, promotions, brand trust and satisfaction of consumers against purchasing decisions (case study of user Honda Vario Muara Bulian district). The number of samples in the study was 80 respondents and convience method using sampling. This research method using multiple linear regression test analysis. The results of this study showed that the quality of the products, promotions, brand and trust our satisfaction of influential consumers significantly to purchasing decisions. Test the quality of the data used in this study using the test validity and reliability as for testing the validity, reliability, while for hypothesis testing in this study using a coefficient determination test, test and test $F$ T. multiple linear regression test results it can be concluded that there is a significant influence of the variable quality of products, promotions, brand, trust and satisfaction of consumers against purchasing decisions.
\end{abstract}

Keyword: product quality, promotion, brand Trust, satisfaction of consumers and purchasing decisions.

\section{PENDAHULUAN}

Perilaku pembelian seseorang dapat dikatakan sesuatu yang unik, karena preferensi dan sikap terhadap obyek setiap orang berbeda. Selain itu konsumen berasal dari beberapa segmen, sehingga apa yang diinginkan dan yang dibutuhkan juga berbeda. Masih banyak faktor yang berpengaruh terhadap keputusan pembelian. Produsen perlu memahami perilaku konsumen terhadap produk atau merek yang ada di pasar, selanjutnya perlu dilakukan berbagai cara untuk membuat konsumen tertarik terhadap produk yang dihasilkan. Dalam proses penyampaian produk kepada pelanggan dan untuk mencapai optimal, maka kegiatan pemasaran dijadikan tolak ukur oleh setiap perusahaan. sebelum meluncurkan produknya perusahaan harus mampu melihat atau mengetahui

\footnotetext{
${ }^{1}$ STIE Graha Karya Muara Bulian
}

apa yang dibutuhkan oleh konsumen. Sehingga sudah sewajarnya jika segala kegiatan perusahaan harus selalu dicurahkan untuk memenuhi kebutuhan konsumen dan kemudian konsumen akan memutuskan membeli produk tersebut dan pada akhirnya tujuan perusahaan yaitu memperoleh laba akan tercapai.

Kualitas produk memiliki dampak langsung pada kinerja produk oleh karena itu kualitas berhubungan erat dengan nilai dan keputusan pembelian dari konsumen, dalam arti sempit kualitas bisa didefinisikan sebagai " bebas dari kerusakan", kualitas berarti kemampuan produk untuk melaksanakan fungsinya : termasuk keawetan, keandalan, ketepatan, kemudahan dipergunakan dan diperbaiki. Kualitas harus diukur dari segi persepsi atau tanggapan dari pembeli, kualitas merupakan peluang untuk bersaing (Kotler: 2002). Bagian yang penting dari Analisis Pengaruh Kualitas Produk, Promosi, Kepercayaan Merek, dan Kepuasan Konsumen terhadap Keputusan Pembelian Sepeda Motor Honda Vario (Studi pada pengguna Motor Honda Vario di Kecamatan Muara Bulian) 
instrument pemasaran adalah pesan yang dikomunikasikan kepada calon pembeli melalui berbagai unsure yang terdapat dalam program promosi. Promosi penjualan, salah satu kunci dalam kampanye pemasaran serta insentif yang berbeda, kebanyakan jangka pendek, yang dirancang untuk menstimulasi pembelian produk khusus atau layanan yang lebih cepat dan lebih besar oleh pelanggan atau perdagangan (Philip Kotler, Swee Hoong Ang, Siew Meng Leon, dan Chin Tiong Tan, 2005: 369). Salah satu unsure paduan pemasaran yang paling tepat adalah pengolahan produk dan promotion mix dan personal selling. Menurut Rina (2009:30), promosi merupakan intensif jagka pendek untuk mendorong pembelian atau penjualan dari suatu produk dan jasa.

Untuk lebih memperkenalkan produknya Honda gencar melakukan kegiatan promosi untuk menarik minat beli konsumen, diantaranya membuat iklan melalui media cetak ataupun elektronik, menyebarkan selebaran kepada masyarakat, mengadakan pertunjukkan music, mengadakan service gratis bagi pengguna sepeda motor Honda, dan lain-lain, iklan didasari pada informasi. Menurut Sodik (2004) mengembangkan perilaku konsumen dengan menetapkan tiga faktor yang berpengaruh terhadap perilaku konsumen. Faktor pertama yang berpengaruh pada konsumen adalah stimuli. Stimuli menunjukkan penerimaan informasi oleh konsumen dan pemprosesan informasi terjadi saat konsumen meliputi persepsi, sikap, manfaat serta karakteristik konsumen (demografi, kepribadian, dan gaya hidup). Pengaruh yang ketiga respon konsumen yaitu hasil dari proses keputusan konsumen dan suatu pertimbangan yang menyeluruh dari semua faktor diatas.

Kehidupan masyarakat modern saat ini tururt mempengaruhi pola perilaku masyarakat dalam pembelian. Kehidupan modern seringkali ditentukan dengan gaya hidup yang selalu mengikuti trend atau perkembangan jaman. Dalam kondisi seperti ini, keputusan memilih merek turut berperan dalam gaya hidup modern, sehingga keinginan untuk membeli produk yang bermerek turut mewarnai pola konsumsi seseorang. Merek yang telah mapan biasanya dijadikan symbol sebagai suatu produk sukses, sehingga ekuitas merek turut berpengaruh terhadap kondisi emosional konsumen. Kepuasan adalah tingkat perasaan seorang setelah membandingkan kinerja yang dirasakan dibandingkan dengan harapan, jadi tingkat kepuasan adalah fungsi dari perbedaan antara kinerja yang dirasakan dengan harapan, pelanggan dapat mengalami salah satu dari tiga tingkat kepuasan secara umum. Menciptakan suatu harapan kepada pelanggan dilihat pada pengalaman membeli pelanggan dimasa lalu, pendapat rekan dan kolega, dan informasi serta janji pemasar dan pesaing, Kotlrer an Amstrong (2004:793). Kepuasan atau ketidak puasan konsumen terhadapa produk akan member umpan balik berupa tingkah laku setelah pembelian. Apabila konsumen puas, ia mungkin akan membeli lagi produk tersebut dikemudian hari.

Perumusan masalah dalam penelitian ini adalah sebagai berikut: 1) Apakah variabel kualitas produk berpengaruh secara parsial dan signifikan terhadap keputusan pembelian konsumen terhadap produk Honda Vario?; 2) Apakah variabel promosi berpengaruh secara parsial signifikan terhadap terhadap Keputusan Pembelian Sepeda Motor Honda Vario (Studi pada pengguna Motor Honda Vario di Kecamatan Muara Bulian) 
keputusan pembelian produk Honda Vario?; 3) Apakah variabel kepercayaan merek berpengaruh secara parsial signifikan terhadap keputusan pembelian?; 4) Apakah variabel kepuasan konsumen berpengaruh secara parsial signifikan terhadap keputusan pembelian produk sepeda motor Honda vario?; 5) Apakah variabel kualitas produk, promosi, kepercayaan merek dan kepuasan konsumen berpengaruh secara simultan da signifikan terhadap keputusan pembelian produk sepeda motor Honda Vario?

\section{TINJAUAN PUSTAKA \\ Pengertian pemasaran dan konsep pemasaran}

Pemasaran adalah proses sosial dan manajerial dimana individu dan kelompok memperoleh apa yang mereka butuhkan dan inginkan melalui pencapaian dan pertukaran produk serta nilai dengan pihak lain, Kotler (2002:7). Menurut Dharmmesta dan Irawan, (200:10) bahwa konsep pemasaran adalah suatu falsafah bisnis yang menyatakan bahwa kepuasan kebutuhan konsumen merupakan syarat ekonomi dan social bagi kelangsungan hidup perusahaan.

\section{Kualitas Produk}

Menurut Kotler dan Amstrong, (2004) Kualitas adalah karakteristik dari produk dalam kemampuan untuk memenuhi kebutuhan-kebutuhan yang telah ditentukan dan bersifat laten. Kualitas dalam pandangan konsumen adalah hal yang mempunyai ruang lingkup tersendiri yang berbeda dengan kualitas dalam pandangan produsen saat mengeluarkan suatu produk yang biasa dikenal kualitas sebenarnya.

\section{Promosi}

Pengertian menurut Saladin (2001:123) promosi adalah suatu komunikasi informasi penjualan dan pembeli yang bertujuan untuk merubah sikap dan tingkah laku pembeli, yang tadinya tidak mengenal menjdai mengenal pembeli dan tetap mengingat produk tersebut.

Definision promosi penjualan menurut American Marketing Association (AMA) dalam setiadi, (2003:256), yaitu : sales promotion is media and non media marketing pressure applied for a predetermined, limited period of time in order to stimu;ate trial, increase demand or improve product quality. Definisi diatas menunjukkan bahwa promosi penjualan mengandung pengertian yakni upaya pemasaran yang bersifat media dan non media untuk merangsang coba-coba dari konsumen, meningkatkan permintaan dari konsumen atau untuk untuk memperbaika kualitas produk. Hal yang terpenting yaitu, bahwa upaya pemasaran melalui promosi penjualan dilakukan dalam jangka pendek.

Menurut Kotler, (2002:323) alatalat promosi penjualan meliputi :

1. Alat Promosi Konsumen utama mencakup contoh produk (sample), kupon, pengembalian uang tunai, kumpulan harga, bingkisan premium, pemasangan iklan khusus, penghargaan pelanggan, pameran dan demonstrasi si titik pengembalian, dan kontes, undian berhadiah, dan permainan.

2. Alat Promosi Pedagangan. dapat membujuk perantara perdagangan supaya menjual merek, memberinya ruang dirak, mempromosikannya dalam pemasangan iklan, dan mendorong kepada konsumen. Ruang rak begitu langka dewasa ini sehingga 
pabrikan sering harus menawarkan potongan harga, tunjangan, jaminan membeli kembali, atau barang gratis kepada para pengecer dan pedagang besar supaya bersedia menempatkan produk-produknya dirak dan mempertahankan disana.

3. Alat Promosi Bisnis. Promosi Bisnis itu digunakan untuk menghasilkan pelopor bisbis, mendorong pembelian, mendorong penghargaan kepada pelanggan, dan memotivasi tenaga penjualan.

\section{Kepercayaan Merek}

Menurut Luarn dan Lin (2003) dalam Erna Ferrinadewi (2008:147) kepercayaan adalah sejumlah keyakinan spesifik terhadap integritas (kejujuran pihak yang dipercaya dan kemampuan menempati janji). Benevolence (perhatian dan motivasi yang bertindak sesuai dengan kepentingan yang mempercayai mereka). Competency (kemampuan pihak yang dipercaya untuk melaksanakan kebutuhan yang mempercayai) dan predictability (konsistensi perilaku pihak yang dipercaya). Menurut Gurviez dan Korchia (2003) dalam aulia Damayanti (2010:27) dari sudut pandang konsumen kepercayaan merek merupakan variabel psikologis yang mencerminkan sejumlah akumulasi asumsi awal yang melibatkan kredibilitas, integritas, dan benevolence, yang dilekatkan pada merek tertentu.

\section{Kepuasan Konsumen}

Kotler dan Amstrong (2004:10) kepuasan pelanggan tingkatan dimana anggapan kinerja (perceived performance) produk akan sesuai dengan harapan seorang pembeli. Bila kinerja produk jauh lebih rendah dibandingkan dengan harapan pelanggan, pembelinya tidak puas. Bila kinerja sesuai dengan harapan atau melebihi harapan, pembelinya merasa puas atau merasa amat gembira.

Dalam pengujian kepuasan pelanggan dibutuhkan suatu manajemen hubungan (costumer relationship management-CRM), yang dimana dalam manajemen hubungan pelanggan adalah keseluruhanproses membangun dan memelihara hubungan pelanggan yang menguntungkan dengan menghantarkan nilai dan kepuasan yang unggul.

\section{Keputusan Pembelian}

Pengambilan keputusan untuk melakukan pembelian produk atau jasa diawali oleh adanya kesadaran atas pemenuhan kebutuhan dan keinginan untuk menyadari adanya masalah selanjutnya, maka konsumen akan melakukan beberapa tahap yang pada akhirnya sampai pada tahap evaluasi pasca pembelian, Bambang Pranto (2008).

\section{METODOLOGI PENELITIAN}

Penelitian ini dilakukan untuk menganalisis pengaruh kualitas produk, promosi, kepercayaan merek, dan kepuasan konsumen terhadap keputusan pembelian produk sepeda mototr Honda Vario. Adapun teknik pengambilan sampel yang digunakan dalam penelitian ini adalah teknik convenience sampling merupakan teknik penentuan sampel berdasarkan kebetulan saja, anggota populasi yang ditemui peneliti dan bersedia menjadi responden untuk menjadi sampel atau peneliti memilih orang-orang terdekat saja. Menurut Sugiono (2000:77) convience sampling adalah teknik penentuan sampel berdasarkan kebetulan. Sedangkan untuk ukuran sample penelitian menurut Roscoe dalam buku research methods for business (Sugiono, 2000:52) menyatakan 
bahwa ukuran sampel yang layak dalam penelitian adalah antara 30 sampai 500, makin besar tingkat kesalahan maka akan semakin kecil yang diperlukan dan sebaliknya makin kecil tingkat kesalahan, maka akan semakin besar jumlah anggota sampel yang diperlukan. Sampel yang diambil sebanyak 60 orang dari pengguna motor merek Honda Vario di Muara Bulian.

\section{Metode Pengumpulan Data}

Metode penulisan yang digunakan dalam penelitian ini adalah sebagai berikut: data primer (kuisioner dan wawancara) dan daqta sekunder (penelitian Kepustakaan dan Penelitian Lapangan)

\section{Metode Analisis}

Kuisioner penelitian

ini menggunakan skala likert, menurut Syofian Siregar (2010:138), skala likert adalah skala yang digunakan untuk mengukur sikap, pendapat, dan persepsi seseorang tentang suatu objek atau fenomena tertentu. Dengan menggunakan skala likert, maka variabel yang akan diukur dijabarkan dari variabel menjadi sub variabel, dari sub variabel dijabarkan menjadi sub indicator yang dapat diukur. Alat analisa yang digunakan yaitu :

\section{Uji Validitas dan reliabilitas}

Validitas atau kesahihan adalah menujukkan sejauh mana suatu alat ukur mampu mengukur apa yang ingin diukur (valid measure if it successfully measure the phenomenon) Syofia Siregar (2010:162)

Realibilitas adalah untuk mengetahui sejauh mana hasil pengukuran tetap konsisten, apabila dilakukan pengukuran dua kali atau lebih terhadap gejala yang sama dengan menggunakan alat pengukur yang sama pula.

\section{Analisis Regresi Berganda}

Analisis regresi berganda merupakan regresi linier dengan menggunakan sebuah variabel terikat $(\mathrm{Y})$ dihubungkan dengan dua atau lebih variabel $\left(\mathrm{X}_{1}, \mathrm{X}_{2}\right)$. Persamaan dari regresi linier berganda adalah sebagai berikut :

$\mathrm{Y}=\mathrm{a}+\mathrm{b}_{1} \mathrm{X}_{1}+\mathrm{b}_{2} \mathrm{X}_{2}+\mathrm{b}_{3} \mathrm{X}_{3}+\mathrm{b}_{4} \mathrm{X}_{4}+\mathrm{e}$

Keterangan :

$\mathrm{Y} \quad=$ keputusan pembelian

a = bilangan konstanta

$\mathrm{b}=$ koefisien regresi

$\mathrm{X}_{1} \quad=$ kualitas Produk

$\mathrm{X}_{2} \quad=$ Promosi

$\mathrm{X}_{3} \quad=$ kepercayaan merek

$\mathrm{X}_{4}=$ Kepuasan konsumen

e $\quad=$ error

\section{Uji Hipotesis}

Uji T atau Parsial

Uji ini digunakan untuk menguji kemaknaan koefisien parsial. Apabila thitung < ttabel maka Ho diterima, sebaliknya jika $\mathrm{t}$ hitung $>\mathrm{t}$ tabel maka Ho ditolak.

\section{Uji F (Simultan)}

Uji ini dilakukan untuk mengetahui apakah semua variabel independen mempunyai pengaruh yang sama terhadap variabel dependen. Untuk membuktikan kebenaran hipotesis digunakan uji distribusi $\mathrm{F}$ dengan cara membandingkan antara nilai Fhitung apabila perhitungan Fhitung > Ftabel maka Ho ditolak sehingga dapat dikatakan bahwa variabel bebas dari regresi dapat menerangkan variabel terikat secara serentak dan sebaliknya.

\section{Operasional Variabel (Variabel Bebas dan Variabel Terikat)}

Koefisien korelasi digunakan untuk melihat drajat hubungan antara variabel 
bebas dengan variabel terikat secara parsial. Jika koefisien korelasi (r) mendekati 1 atau seratus persen maka de rajat hubungannya sangat kuat sedangkan jika koefisien (r) mendekati 0 (nol) maka derajat dapat hubungannya sangat lemah.

Koefisien determinasi digunakan untuk memperkirakan kontribusi variabel bebas terhadap naik turunnya variabel terikat. Jika koefisien determinasi $(\mathrm{R} 2)=1$, berarti presentasi sumbangan variabel $\mathrm{X}$ terhadap turunnya Y sebesar $100 \%$ dan tidak ada faktor lain yang mempengaruhi variabel $\mathrm{Y}$, sedangkan jika koefisien determinasi $(\mathrm{R} 2)=0$ (nol), berarti persemaan regresi tidak dapat digunakan untuk membuat ramalan terhadap $\mathrm{Y}$.

\begin{tabular}{llll} 
Variabel & \multicolumn{2}{l}{ tabel reliabelitas } & \\
& $\begin{array}{l}\text { Cronbach's } \\
\text { Alpha }\end{array}$ & $\begin{array}{l}\text { Taraf } \\
\text { Signifikan }\end{array}$ & Keterangan \\
\hline Kualitas Produk & 0,710 & 0,6 & Reliabel \\
Promosi & 0.685 & 0,6 & Reliabel \\
Kepercayaan merek & 0,723 & 0,6 & Reliabel \\
Kepuasan konsumen & 0,715 & 0,6 & Reliabel \\
Keputusan pembelian & 0,744 & 0,6 & Reliabel \\
\hline
\end{tabular}

Sumber : Data Primer yang telah diolah

\section{HASIL DAN PEMBAHASAN Uji Reliabilitas dan Validitas}

Uji realibilitas ini dilakukan untuk menguji konsistensi dari responden melalui pertanyaan yang diberikan, hasil dari pengujian reliabilitas digunakan untuk mengetahui apakah instrumend penelitian yang dipakai dapat digunakan berkali-kali pada waktu yang berbeda. Uji validitas digunakan untuk mengukur sah atau valid tidaknya suatu kuesioner. Suatu kuesioner dikatakan valid jika pertanyaan pada kuesioner mampu untuk mengungkapkan sesuatu yang akan diukur oleh kuisioner tersebut. Dapat kita lihat pada tabel dibawah ini :

Tabel validitas

\begin{tabular}{lcccc}
\hline variabel & Pertanyaan & $\begin{array}{c}\text { Product } \\
\text { momen }(\mathbf{r})\end{array}$ & R Tabel & Ket \\
\hline Kualitas & 1 & 0,691 & 0,2500 & Valid \\
Produk & 2 & 0,674 & 0,2500 & Valid \\
& 3 & 0,482 & 0,2500 & Valid \\
& 4 & 0,517 & 0,2500 & Valid \\
& 5 & 0,593 & 0,2500 & Valid \\
& 6 & 0,688 & 0,2500 & Valid \\
& 7 & 0,702 & 0,2500 & Valid \\
& 8 & 0,678 & 0,2500 & Valid \\
& 9 & 0,658 & 0,2500 & Valid \\
& 10 & 0,574 & 0,2500 & Valid \\
Promosi & 11 & 0,715 & 0,2500 & Valid \\
& 12 & 0,688 & 0,2500 & Valid \\
& 1 & 0,645 & 0,2500 & Valid \\
& 2 & 0,638 & 0,2500 & Valid \\
& 3 & 0,682 & 0,2500 & Valid
\end{tabular}




\begin{tabular}{lllll}
\hline & 4 & 0,742 & 0,2500 & Valid \\
& 5 & 0,739 & 0,2500 & Valid \\
Kepercayaa & 6 & 0,651 & 0,2500 & Valid \\
n merek & 1 & 0,761 & 0,2500 & Valid \\
& 3 & 0,803 & 0,2500 & Valid \\
& 4 & 0,715 & 0,2500 & Valid \\
& 5 & 0,688 & 0,2500 & Valid \\
Kepuasan & 6 & 0,753 & 0,2500 & Valid \\
konsumen & 1 & 0,674 & 0,2500 & Valid \\
& 2 & 0,741 & 0,2500 & Valid \\
& 3 & 0,702 & 0,2500 & Valid \\
& 4 & 0,649 & 0,2500 & Valid \\
& 5 & 0,564 & 0,2500 & Valid \\
& 6 & 0,703 & 0,2500 & Valid \\
& 7 & 0,688 & 0,2500 & Valid \\
& 8 & 0,691 & 0,2500 & Valid \\
Keputusan & 9 & 0,674 & 0,2500 & Valid \\
pembelian & 1 & 0,642 & 0,2500 & Valid \\
& 2 & 0,748 & 0,2500 & Valid \\
& 3 & 0,784 & 0,2500 & Valid \\
& 4 & 0,654 & 0,2500 & Valid \\
& 5 & 0,517 & 0,2500 & Valid \\
& 5 & 0,718 & 0,2500 & Valid \\
\hline
\end{tabular}

Sumber : Data Primer yang telah diolah

Dari hasil output dapat dilihat dari Alpha lebih besar dari nilai Alpha yaitu butir pertanyaan kualitas produk, Croncach Alpha > 0,6 maka dapat promosi, kepercayaan merek, kepuasan disimpulkan bahwa semua butir konsumen dan keputusan pembelian pertanyaan dari instrument promosi semua nilai rhitung lebih besar dari adalah valid dan reliabel. 0,2500 dan juga nilai total Cronbach Uji regresi Berganda

\begin{tabular}{|c|c|c|c|c|c|c|}
\hline \multicolumn{7}{|c|}{ Coefficients $^{\mathrm{a}}$} \\
\hline & \multirow{2}{*}{ Model } & \multicolumn{2}{|c|}{$\begin{array}{l}\text { Unstandardized } \\
\text { Coefficiente }\end{array}$} & \multirow{2}{*}{$\begin{array}{c}\text { Standardized } \\
\text { Coefficients } \\
\text { Beta }\end{array}$} & \multirow[b]{2}{*}{$\mathrm{t}$} & \multirow[b]{2}{*}{ sig } \\
\hline & & $\mathrm{B}$ & Std.Error & & & \\
\hline 1 & (Constant) & 2.890 & 1.028 & & 2.811 & .007 \\
\hline & TKP & .119 & .044 & .338 & 2.739 & .008 \\
\hline & $\mathrm{TP}$ & -.165 & .059 & -.125 & -2.798 & .007 \\
\hline & TKM & .827 & .051 & 1.003 & 16.090 & .000 \\
\hline & TKK & .088 & .042 & .136 & 2.088 & .041 \\
\hline
\end{tabular}

a. Dependent Variable : TKPL

Pada output ini, dikemukakan nilai kasus ini, persamaan regresi berganda koefisien dari persamaan regresi dalam yang digunakan adalah:

$Y=2.890+0.199 X_{1}-0.165 X_{2}+0.827 X_{3}+0.088 X_{4}+e$ 


$$
\begin{array}{ll}
\text { Keterangan : } \\
\mathrm{Y} & =\text { keputusan pembelian } \\
\mathrm{a} & =\text { bilangan konstanta } \\
\mathrm{b} & =\text { koefisien regresi } \\
\mathrm{X}_{1} & =\text { kualitas Produk } \\
\mathrm{X}_{2} & =\text { Promosi } \\
\mathrm{X}_{3} & =\text { kepercayaan merek } \\
\mathrm{X}_{4} & =\text { Kepuasan konsumen } \\
\mathrm{e} & =\text { error }
\end{array}
$$

Pada regresi berganda ini merupakan model terbaik, karena independen yang dimasukan dalam persamaan regresi merupakan yang memberikan pengaruh terhadap variabel dependennya. Berdasrakan data diatas bahwa variabel yang paling dominan ygberpengaruh terhadap keputusan pembelian (Y) adalah variabel kepercayaan merek (X3) yang memiliki nilai koefisien regresi sebesar 0,827 .

\section{Uji Parsial (Uji t)}

Pengujian hipotesis secara parsial dilakukan untuk mengetahui ada tidaknya pengaruh masing-masing variabel independennya (kualitas produk, promosi, kepercayaan merek dan kepuasan konsumen) terhadap variabel dependennya (Keputusan Pembelian) yang dilakukan dengan uji $\mathrm{T}$.

Uji T pada kolom Kualitas produk menghasilkan t-hitung 2.739 dengan tingkat signifikasi 0,008 jauh lebih kecil dari level significance yang digunakan yakni sebesar 0,05 (5\%). 2.739>1.671 artinya nilai Kualitas produk pada $t$ hitung lebih besar dari t tabel sehingga secara parsial yang menyatakan ada pengaruh variabel Kualitas produk terhadap Keputusan Pembelian. Uji t pada kolom Promosi menghasilkan thitung -2.798 dengan tingkat signifikasi 0,007 jauh lebih kecil dari level significance yang digunakan yakni sebesar 0,05 (5\%). - 2.798<.1.671 artinya nilai Promosi pada t hitung lebih kecil dari t tabel sehingga secara parsial yang menyatakan berpengaruh negatif terhadap Keputusan pembelian. Uji t pada kolom Kepercayaan merek menghasilkan t-hitung 16.090 dengan tingkat signifikasi 0,000 jauh lebih kecil dari level significance yang digunakan yakni sebesar 0,05 (5\%). 16.090>1.671 artinya nilai kepercayaan merek pada $\mathrm{t}$ hitung lebih besar dari $t$ tabel sehingga secara parsial yang menyatakan ada pengaruh variabel kepercayaan merek terhadap Keputusan Pembelian. Uji t pada kolom keputusan konsumen menghasilkan t-hitung 2.088 dengan tingkat signifikasi 0,041 jauh lebih kecil dari level significance yang digunakan yakni sebesar 0,05 (5\%). 2.088>1.671 artinya nilai keputusan konsumen pada $t$ hitung lebih besar dari t tabel sehingga secara parsial yang menyatakan ada pengaruh variabel keputusan konsumen terhadap Keputusan Pembelian.

\section{Uji F (Uji Simultan)}

Pengujian hipotesis secara simultan bertujuan untuk mengukur besarnya pengaruh variabel bebas secara bersama-sama terhadap variabel berikitnya. Hasil hipotesis dalam pengujian ini adalah :

\begin{tabular}{rlrrrrr} 
& \multicolumn{5}{c}{ ANOVA $^{\mathrm{b}}$} \\
\hline \multirow{2}{*}{ Model } & $\begin{array}{c}\text { Sum of } \\
\text { Squares }\end{array}$ & Df & $\begin{array}{c}\text { Mean } \\
\text { Square }\end{array}$ & F & Sig. \\
\hline 1 & Regression & 496.548 & 4 & 124.137 & 373.053 & $.000^{\mathrm{a}}$ \\
& Residual & 18.302 & 55 & .333 & & \\
& Total & 514.850 & 59 & & & \\
\hline
\end{tabular}

a.Predictors : (Constant), TKK,TKP,TP,TKM

Analisis Pengaruh Kualitas Produk, Promosi, Kepercayaan Merek, dan Kepuasan Konsumen terhadap Keputusan Pembelian Sepeda Motor Honda Vario (Studi pada pengguna Motor Honda Vario di Kecamatan Muara Bulian) 
b.Dependent Variabel : TKPL

Pada tabel analisis anova niali Ftabel $=2.54$. nilai $\mathrm{F}$ hitung ditampilkan hasil uji F yang dapat (373.053) > F tabel (2.54) maka dapat dipergunakan untuk memprediksi disimpulkan bahwa keempat variabel konstribusi aspek-aspek variabel kualitas independen yaitu kualitas produk, produk, Promososi, kepercayaan merek Promosi, kepercayaan merek, dan dan kepuasana konsumen terhadap kepuasan konsumen dengan signifikan variabel keputusan pembelian dengan memberikan kontribusi yang besar nilai $\mathrm{F}$ hitung sebesar 373.053 , dengan terhadap variabel keputusan pembelian. tingkat signifikan sebesar $5 \%$ dengan Koefisien Determinasi $\left(R^{2}\right)$

\begin{tabular}{ccccc}
\multicolumn{5}{c}{ Model Summary $^{\mathrm{b}}$} \\
\hline Model & $\mathrm{R}$ & $\mathrm{R}$ Square & $\begin{array}{c}\text { Adjusted R } \\
\text { Square }\end{array}$ & $\begin{array}{c}\text { Std.Error of the } \\
\text { Estimate }\end{array}$ \\
\hline 1 & $.862^{\mathrm{a}}$ & .844 & .835 & .577
\end{tabular}

a. Predictors : (Constant), TKK,TP,TKP,TKM

b. Dependent Variable : TKPL

Dari tampilan outpt diatas besarnya Adjust R2 adalah 0.835 , hal ini berarti $84,4 \%$ variasi keputusan pembelian (TKPL) yang dapat dijelaskan oleh empat variabel independen kualitas produk (TKP), Promosi (TP), kepercayaan merek (TKM), dan sisanya $(100 \%-83,5 \%=17,5 \%)$ dipengaruhi model lainnya.

\section{SIMPULAN}

Berdasarkan pada hasil penelitian dan pembahasan mengenai analisis pengaruh kualitas produk, promosi, kepercayaan merek dan kepuasan konsumen terhadap keputusan pembelian sepeda motor Honda Vario di daerah Muara Bulian, maka dapat disimpulkan secara parsial dan bahwa variabel kualita produk, Promosi, Kepercayaan merek dan kepuasan konsumen terdapat pengaruh yang signifikan terhadap keputusan pembelian. Dimana dapat dilihat dari nilai koefisien Determinasi $\left(\mathrm{R}^{2}\right)$ sebesar $83,5 \%$ pengaruh dari kepuasan konsumen (TKK). Sedangkan

keempat variabel independen terhadap variabel dependent.

\section{DAFTAR PUSTAKA}

Buchari Alma.2004. Manajemen pemasaran dan pemasaran jasa. Alfabeta. Bandung.

Damayanti Aulia.2010 "Pengaruh kepuasan konsumen dan kepercayaan merek terhadap loyalitas merek".

Dharmamesta dan Irawan.2000. "Perilaku beralih merek konsumen dalam pembelian produk otomotif'. Jurnal ekonomi dan bisnis Indonesia. Vol 14.3.h73-88.

Diana Anastasia dan Tjiptono. 2000. “ Prinsip dan dinamika pemasaran."

Ferinadewi Erna. 2008. "merek dan psikologi konsumen".

Kennedy E Jhon dan R. Dermawan Soemanegara.2006."Marketing Comunication" taktik dan strategi. Penerbit PT. Bhuana ilmu popular. Jakarta Barat.

Kotler dan Amstrong. 2008.B. "prinsipprinsip Pemasaran". Edisi 12, jilid

Analisis Pengaruh Kualitas Produk, Promosi, Kepercayaan Merek, dan Kepuasan Konsumen terhadap Keputusan Pembelian Sepeda Motor Honda Vario (Studi pada pengguna Motor Honda Vario di Kecamatan Muara Bulian) 
2, PT. Indeks Gramedia Group, Jakarta.

Kwok. S dan Uncles. M. 2002. "sales Promotion Effectivenes", University of Ne South Wales.

Muafi. 2003. Telaah Bisnis"Volume 4. Juli 2003. Akademi Manajemen Perusahaan YKPN. Yogyakarta.

Pranoto Bambang. 2008."Pengaruh harga dan kualitas produk terhadap keputusan konsumen membeli kendaraan bermotor".

Setiadi. 2003."Perilaku konsumen, konsep dan implikasi untuk strategi dan penelitian pemasaran". Edisi 1, cetakan ke 3 .

Saladin. 2002. "Intisari pemasaran dan unsure-unsur pemasaran".

Sugiono.2005. "Metode penelitian bisnis". CV. Alfabeta, Bandung. 